\section{PULMONARY VASOMOTOR DYSFUNCTION IS PRODUCED WITH CHRONICALLY HIGH PULMONARY BLOOD FLOW}

This study examined the hypothesis that chronic high pulmonary blood flow produces dysfunction of the mechanisms of pulmonary vasorelaxation. A 3:1 left-to-right shunt was created in dogs by bilateral femoral arteryfemoral vein shunts with use of $6 \mathrm{~mm}$ polytetraftuoroethylene grafts. Isolated pulmonary artery rings were studied at the following times: 3 days $(n=2), 2$ weeks $(n=4)$, and 5 months $(n=6)$. Control animals had no shunt. The following mechanisms of pulmonary vasorelaxation were studied in isolated pulmonary artery rings (4 rings from each dog): (1) endothelium-dependent cyclic guanosine monophosphate-mediated relaxation (response to acetylcholine), (2) endothelium-independent cyclic guanosine monophosphate-mediated relaxation (response to sodium nitroprusside), and (3) $\beta$-adrenergic cyclic adenosine monophosphate-mediated relaxation (response to isoproterenol). Stastical analysis was done by analysis of variance. This model of high pulmonary flow did not produce an increase in pulmonary arterial pressure or transpulmonary gradient. However, chronic high pulmonary flow produced progressive dysfunction of all three of these mechanisms of pulmonary vasorelaxation. By 5 months of high pulmonary flow, acetylcholine produced only $36 \% \pm 6 \%$ relaxation versus $95 \% \pm 5 \%$ in control animals $(p<0.05)$. Likewise, sodium nitroprusside produced only $69 \% \pm 6 \%$ relaxation versus $100 \%$ in control animals $(p<0.05)$. Finally, isoproterenol produced only 55\% $\pm 5 \%$ relaxation versus $94 \% \pm 6 \%$ in control animals $(p<0.05)$. We conclude that dysfunction of the mechanisms of pulmonary vasorelaxation may contribute to exaggerated perioperative pulmonary vasoconstriction in the setting of chronic high pulmonary blood flow. (J THORAC CARDIOvaSC SuRG 1996;111:190-7)

David A. Fullerton, MD, Max B. Mitchell, MD, Darrell N. Jones, PhD, A. Maki, MD, and Robert C. McIntyre, Jr., MD, Denver, Colo.
P ulmonary hypertension as a result of increased pulmonary vascular resistance (PVR) remains a significant problem in the treatment of patients undergoing surgical correction of left-to-right intracardiac shunts. Such pulmonary hypertension is one of the most important determinants of perioperative morbidity and mortality and of long-term survival after cardiac operations. ${ }^{1,2}$ The structural changes

From the Division of Cardiothoracic Surgery, University of Colorado, Denver, Colo.

Supported by National Institutes of Health grant R29HL49398.

Received for publication Feb. 28, 1995.

Accepted for publication April 13, 1995.

Address for reprints: David A. Fullerton, MD, Cardiothoracic Surgery, Box C-310, University of Colorado Health Sciences Center, 4200 East Ninth Ave., Denver, CO 80262.

Copyright (c) 1996 by Mosby-Year Book, Inc.

$0022-5223 / 96 \$ 5.00+0 \quad \mathbf{1 2 / 1 / 6 5 6 7 1}$ produced in the pulmonary vascular bed as a result of a left-to-right shunt are well recognized and clearly contribute to the development of such pulmonary hypertension., ${ }^{3,4}$ However, even patients undergoing surgical repair of a left-to-right shunt without advanced pulmonary vascular disease may exhibit significant pulmonary vasoconstriction in the perioperative period. ${ }^{5}$

Net pulmonary vascular tone results from the balance of the mechanisms of pulmonary vasorelaxation and vasoconstriction. If the mechanisms of pulmonary vasorelaxation are impaired, the net pulmonary vascular tone may be tipped in favor of pulmonary vasoconstriction. In addition, impairment of the mechanisms of pulmonary vasorelaxation may result in an exaggerated pulmonary vasoconstricting response to circulating or local vasoconstricting agonists. ${ }^{6}$

The principal intracellular mechanisms of pulmo- 


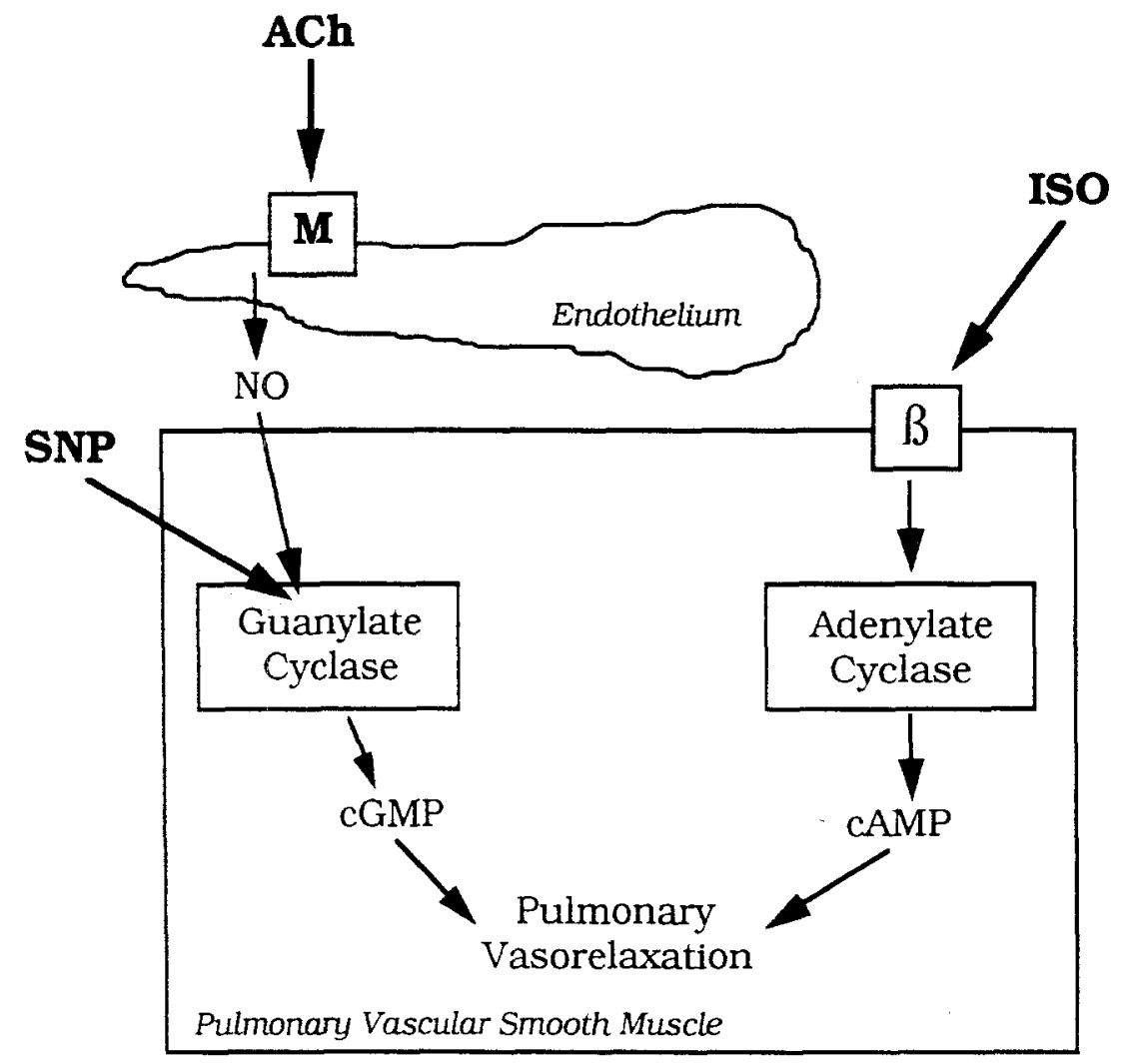

Fig. 1. Mechanisms of pulmonary vasorelaxation are ultimately mediated through either cGMP or cAMP. cGMP is generated when guanylate cyclase is stimulated by endothelium-derived nitric oxide (NO) or by nitric oxide donors such as sodium nitroprusside $(S N P)$. cAMP is generated when adenylate cyclase is stimulated by receptors such as $\beta$-adrenergic receptors $(\beta)$ in response to isoproterenol (ISO). $A C h$, Acetylcholine; $M$, muscarinic receptor.

nary vasorelaxation are ultimately mediated through either guanosine $3^{\prime}, 5^{\prime}$-cyclic monophosphate (cGMP) or adenosine $3^{\prime}, 5^{\prime}$-cyclic monophosphate (cAMP). ${ }^{7}$ As shown in Fig. 1, cGMP-mediated pulmonary vasorelaxation may be achieved through pathways that are endothelium-dependent or endotheliumindependent. Agents such as acetylcholine achieve endothelium-dependent cGMP-mediated pulmonary vasorelaxation by activating muscarinic receptors on the endothelial cell, causing the synthesis and release of nitric oxide, which acts on guanylate cyclase in the subjacent pulmonary vascular smooth muscle cell to generate cGMP. Nitrovasodilators such as sodium nitroprusside relax pulmonary vascular smooth muscle by direct stimulation of pulmonary vascular smooth muscle guanylate cyclase to generate cGMP. On the other hand, agents that are mediated through cAMP, such as isoproterenol, do so by activating $\beta_{1}$-adrenergic membrane receptors on the pulmonary vascular smooth muscle cell, leading to activation of adenylate cyclase and generation of cAMP. The mechanisms by which cGMP and cAMP ultimately achieve relaxation of pulmonary vascular smooth muscle are as yet unclear.

We hypothesized that chronic high pulmonary arterial blood flow as produced by a left-to-right shunt produces dysfunction of the mechanisms of pulmonary vasorelaxation. Therefore the purpose of this study was to examine the following mechanisms of pulmonary vasorelaxation in a canine model of a left-to-right shunt: (1) endothelium-dependent cGMP-mediated pulmonary vasorelaxation (response to acetylcholine), (2) endothelium-independent cGMP-mediated pulmonary vasorelaxation (response to sodium nitroprusside), and (3) $\beta$-adrenergic cAMP-mediated pulmonary vasorelaxation (response to isoproterenol).

The results of this study suggest that in the setting of chronic high pulmonary blood flow, there is a 


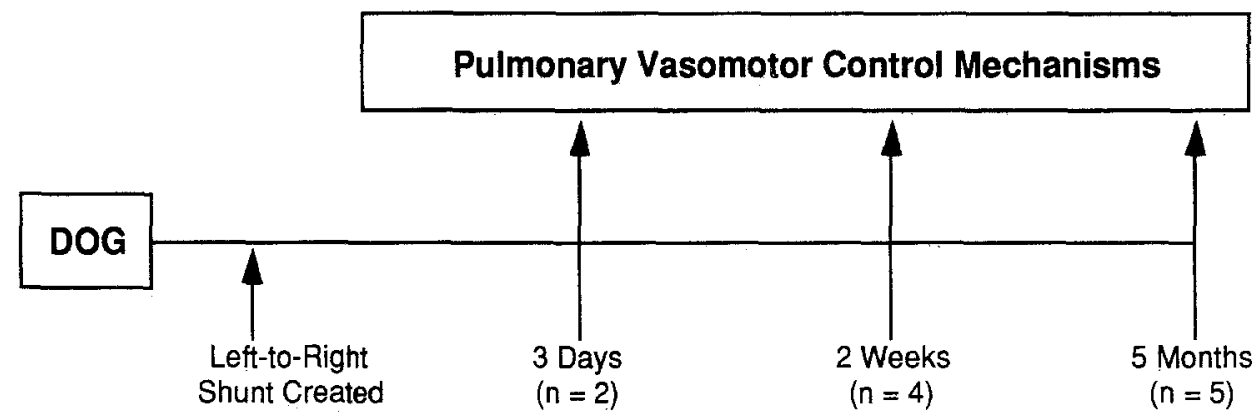

Fig. 2. Experimental protocol. After creation of left-to-right shunt, pulmonary vasomotor control mechanisms were studied at 3 days, 2 weeks, and 5 months.

progressive impairment of both cGMP- and cAMPmediated mechanisms of pulmonary vasorelaxation.

\section{Methods}

All animals received humane care in compliance with the "Principles of Laboratory Animal Care" formulated by the National Society for Medical Research and the "Guide for the Care and Use of Laboratory Animals" prepared by the Institute of Laboratory Animal Resources and published by the National Institutes of Health (NIH Publication No. 86-23, revised 1985).

Experimental protocol. Male mongrel dogs (20 to 25 $\mathrm{kg}$ ) were studied. Animals were quarantined in lightcycled rooms in the Animal Care Center of the University of Colorado and allowed dog food and water ad libitum.

Creation of left-to-right shunt. Animals were placed in the supine position and halothane general anesthesia and endotracheal intubation instituted. With use of a strict sterile technique, bilateral groin incisions were made and the femoral arteries and femoral veins were surgically isolated. After systemic heparinization, bilateral femoral arteriovenous fistulas were created with the use of $6 \mathrm{~mm}$ synthetic tube conduits* anastomosed with fine monofilament suture. The fistulas were created in the shape of a gentle loop 6 inches in length. The patency of the conduits was assured at the end of the surgical procedure with Doppler ultrasonographic evaluation. The surgical wounds were closed in appropriate layers and the animals recovered from the surgical procedure in the Animal Care Facility of the University of Colorado. The animals received long-term care in the Animal Care Facility in quiet, humidified, light-cycled rooms and were allowed ad libitum access to food and water up to the time of experimentation. Animals were killed at the following points after creation of the left-to-right shunt: 3 days $(n=2$ dogs), 2 weeks ( $n=4$ dogs), and 5 months ( $n=5$ dogs). Control animals ( $n=5$ dogs) were mongrel dogs of the same size that did not have creation of a left-to-right shunt (Fig. 2).

Animal data collection. Before induction of general anesthesia, the patency of each fistula was assured with

*Gore-Tex brand polytetrafluoroethylene conduit. Gore-Tex is a registered trademark of W, L. Gore \& Associates, Inc., Newark, Del.
Doppler ultrasonographic evaluation. After induction of general endotracheal anesthesia (halothane) and institution of mechanical ventilation, a pulmonary arterial catheter (Abbot Laboratories, Chicago, Ill.) was placed via the right internal jugular vein. Mechanical ventilator settings were fraction of inspired oxygen 0.5 , tidal volume 10 $\mathrm{ml} / \mathrm{kg}$, and rate 10 breaths $/ \mathrm{min}$. A median sternotomy was done. A pressure-monitoring catheter was introduced into the left atrium via the right superior pulmonary vein. Likewise a catheter was placed in the aortic root for continuous monitoring of arterial pressure.

With the animal in a steady-state condition, the following hemodynamic variables were measured and recorded: mean aortic pressure, pulmonary arterial pressure (mean, systolic, diastolic), and left atrial pressure. These data were used to calculate the transpulmonary gradient, which was used as a parameter of PVR. To calculate the magnitude of the left-to-right shunt by oximetric data, blood specimens were drawn simultaneously from the aortic root, main pulmonary artery, superior vena cava, and left atrium for blood gas determination. Blood gas specimens were collected in $1 \mathrm{ml}$ heparinized glass syringes with strict attention paid to ensure the blood specimens were collected without exposure to atmosphere. These syringes of blood were immediately placed on ice and blood gas oxygen saturation was immediately determined (Radiometer OSM 3, Copenhagen, Denmark).

The animals were then systemically heparinized (250 units $/ \mathrm{kg}$ ). Ten minutes after heparinization, the right lung was surgically explanted, and the animals were killed with an injection of intravenous $\mathrm{KCl}$. Pulmonary arterial rings were cut from the explanted lung.

Pulmonary artery ring preparation. With the use of a dissecting microscope, four third-order pulmonary arteries (approximately $1 \mathrm{~mm}$ diameter) were dissected from each lung ( 2 pulmonary arteries were dissected from the upper lobe and 2 pulmonary arteries were dissected from the lower lobe). Under dissecting microscope magnification, the surrounding tissue was gently dissected away from the pulmonary arteries. The pulmonary arteries were then each cut into rings 3 to $4 \mathrm{~mm}$ wide. Great care was taken during this process to avoid stretching the vessel, which might cause endothelial injury. The pulmonary arterial rings were suspended on fine wire tensiometers in 
Table I. Oximetric and hemodynamic data

\begin{tabular}{lcccc}
\hline & Control & 3 Days & 2 Wk & 5 Mo \\
\hline $\mathrm{S}_{\mathrm{A}} \mathrm{O}_{2}(\%)$ & 100 & 100 & 100 & 100 \\
$\mathrm{~S}_{\mathrm{SV}} \mathrm{O}_{2}(\%)$ & $65 \pm 4$ & $63 \pm 5$ & $62 \pm 5$ & $63 \pm 5$ \\
$\mathrm{~S}_{\mathrm{PA}} \mathrm{O}_{2}(\%)$ & $71 \pm 2$ & $92 \pm 2$ & $92 \pm 2$ & $91 \pm 3$ \\
$\mathrm{~S}_{\mathrm{PV}} \mathrm{O}_{2}(\%)$ & 100 & 100 & 100 & 100 \\
$\mathrm{pH}$ & $7.38 \pm 0.03$ & $7.39 \pm 0.03$ & $7.38 \pm 0.02$ & $7.38 \pm 0.03$ \\
$\mathrm{Hemoglobin}(\mathrm{gm} / \mathrm{dl})$ & $13 \pm 3$ & $14 \pm 3$ & $13 \pm 2$ & $13 \pm 3$ \\
$\mathrm{MAP}(\mathrm{mm} \mathrm{Hg})$ & $74 \pm 6$ & $76 \pm 8$ & $72 \pm 4$ & $75 \pm 4$ \\
$\mathrm{PAS}(\mathrm{mm} \mathrm{Hg})$ & $20 \pm 1$ & $20 \pm 2$ & $19 \pm 2$ & $20 \pm 2$ \\
$\mathrm{PAD}(\mathrm{mm} \mathrm{Hg})$ & $12 \pm 1$ & $12 \pm 1$ & $12 \pm 1$ & $11 \pm 1$ \\
$\mathrm{PAM}(\mathrm{mm} \mathrm{Hg})$ & $15 \pm 1$ & $15 \pm 1$ & $14 \pm 1$ & $14 \pm 1$ \\
$\mathrm{LAP}(\mathrm{mm} \mathrm{Hg})$ & $3 \pm 1$ & $3 \pm 1$ & $11 \pm 1$ & $3 \pm 1$ \\
$\mathrm{TPG}(\mathrm{mm} \mathrm{Hg})$ & $12 \pm 1$ & $12 \pm 1$ & $11 \pm 1$ \\
\hline
\end{tabular}

Values are mean plus or minus standard error of the mean. $S_{A} O_{2}$, Aortic blood saturation; $S_{S V} O_{2}$, superior vena cava blood saturation; $S_{P_{A}} O_{2}$, pulmonary arterial blood saturation; $S_{P V} O_{2}$, pulmonary venous blood saturation; $M A P$, mean aortic blood pressure; $P A S$, systolic pulmonary artery pressure; $P A D$, diastolic pulmonary artery pressure; $P A M$, mean pulmonary artery pressure; $L A P$, left arterial pressure; $T P G$, transpulmonary gradient.

individual $10 \mathrm{ml}$ organ chambers. The organ chambers were surrounded by water jackets and continually warmed to $37^{\circ} \mathrm{C}$. Ring tension was determined by use of a force-displacement transducer (Grass FTO3, Grass Instruments Co., Quincy, Mass.) attached to each tensiometer apparatus. Force displacement was recorded at 0.67 $\mathrm{Hz}$ with use of a MacLab Data Interface Module (ADI Instruments, Milford, Mass.) on a Macintosh IIci computer (Apple Inc., Cupertino, Calif.). The organ chambers were filled with Earle's balanced salt solution and continuously bubbled with gas composed of $21 \%$ oxygen, $5 \%$ carbon dioxide, and balanced nitrogen, producing an oxygen tersion $\left(\mathrm{PO}_{2}\right)$ of 110 to $115 \mathrm{~mm} \mathrm{Hg}$ and a $\mathrm{pH}$ of 7.36 to 7.40. Earle's balanced salt solution is a standard physiologic salt solution and contains $\mathrm{CaCl}_{2} 1.80 \mathrm{mmol} / \mathrm{L}$, $\mathrm{MgSO}_{4}$ (anhydrous) $0.83 \mathrm{mmol} / \mathrm{L}, \mathrm{KCl} 5.36 \mathrm{mmol} / \mathrm{L}, \mathrm{NaCl}$ $116.34 \mathrm{mmol} / \mathrm{L}, \mathrm{NaPO}_{4} 0.40 \mathrm{mmol} / \mathrm{L}$ (dibasic), D-glucose $5.50 \mathrm{mmol} / \mathrm{L}, \mathrm{NaHCO}_{3} 19.04 \mathrm{mmol} / \mathrm{L}$, and phenol red $\mathrm{Na}$ $0.03 \mathrm{mmol} / \mathrm{L}$ (as $\mathrm{pH}$ indicator).

The optimal resting tension (passive load) of pulmonary arterial rings of this size was determined to be $750 \mathrm{mg}$ in a separate series of experiments in which isolated pulmonary arterial rings were suspended at passive loads ranging from $500 \mathrm{mg}$ to $1000 \mathrm{mg}$ before phenylephrine $10^{-8} \mathrm{~mol} / \mathrm{L}$ was added to the organ chamber bath. The passive load tension that resulted in the highest tension generated in response to phenylephrine was $750 \mathrm{mg}$. Therefore, for subsequent studies, a passive load of $750 \mathrm{mg}$ tension was used. The rings were suspended at a tension of $750 \mathrm{mg}$ for 90 minutes, during which time the Earle's balanced salt solution was changed in each organ chamber every 15 minutes. A given ring was preconstricted with phenyleph. rine $10^{-8} \mathrm{~mol} / \mathrm{L}$ to a tension of 350 to $400 \mathrm{mg}$. There was no difference in response to phenylephrine among the groups studied. Once the ring tension reached a steady state in response to phenylephrine a given vasorelaxing agent was added to the organ chamber. Acetylcholine, sodium nitroprusside, and isoproterenol have each previously been shown to achieve maximal relaxation to phenylephrine-induced pulmonary arterial ring tension at a dose of $10^{-6} \mathrm{~mol} / \mathrm{L}^{8,9}$ The vasorelaxing responses to acetylcholine $10^{-6} \mathrm{~mol} / \mathrm{L}$, sodium nitroprusside $10^{-6}$ $\mathrm{mol} / \mathrm{L}$, and isoproterenol $10^{-6} \mathrm{~mol} / \mathrm{L}$ were then determined in each ring in random order. After each agent was tested, the organ chambers were flushed several times and the rings allowed to reach a steady state again before the rings were once again preconstricted with phenylephrine to test the next vasorelaxing agent. Four pulmonary arterial rings from each lung were studied at each time of data collection.

\section{Mathematical formulas}

Transpulmonary gradient (millimeters of mercury) $=$

$$
\begin{gathered}
\text { Mean pulmonary artery pressure } \\
- \text { Left atrial pressure }
\end{gathered}
$$

Left-to-right shunt (pulmonic flow/systemic flow) $=$

$$
\begin{gathered}
\text { Aortic saturation (percent) - } \\
\text { Superior vena cava saturation (percent) } \\
\begin{array}{c}
\text { Pulmonary venous saturation (percent) - } \\
\text { Pulmonary arterial saturation (percent) }
\end{array}
\end{gathered}
$$

Statistical analyses. Statistical analyses were done with a Macintosh Quadra 650 computer (Apple Inc.) and StatView software (Brain Power, Inc., Calabasas, Calif.). Data are presented as mean plus or minus 1 standard error of the mean of the number of pulmonary rings studied at each point of data collection. Four pulmonary artery rings were obtained from each animal, and the number of animals studied at each point of data collection is shown in Fig. 2. Statistical evaluation used standard one-way analysis of variance with post-hoc BonferroniDunn test. A $p$ value of less than 0.05 was accepted as statistically significant.

\section{Results}

All dogs survived without complication up to the designated time of study. As calculated by the oximetric data, this model produced approximately a 3:1 left-to-right shunt (Table I). Thus this model 


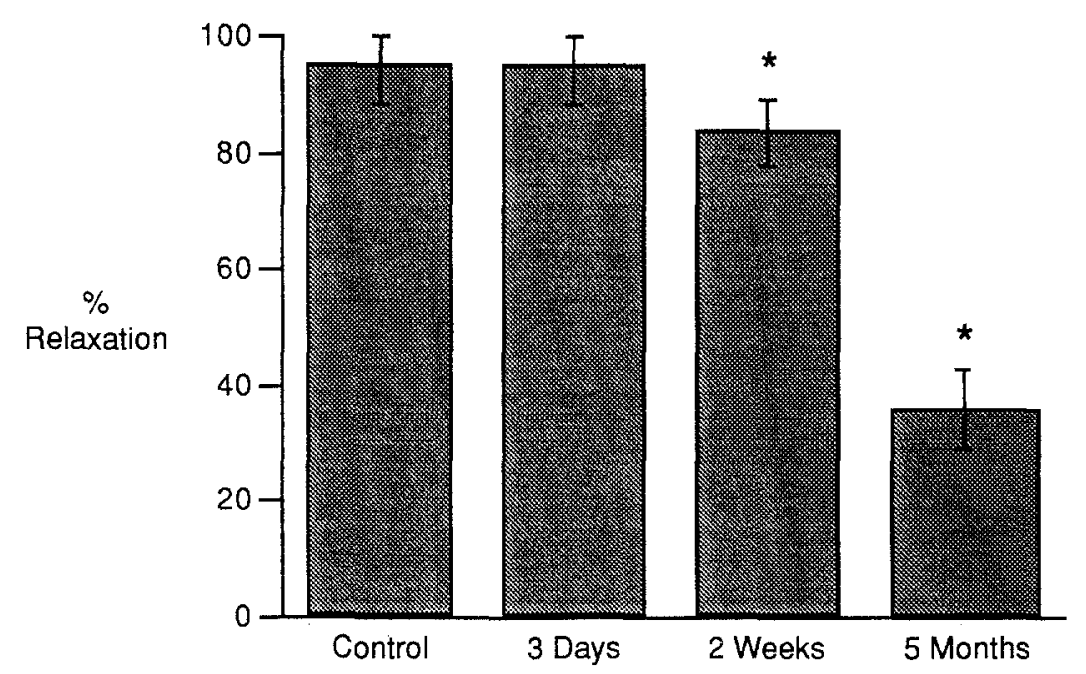

Fig. 3. Endothelial-dependent CGMP-mediated pulmonary vasorelaxation (response to acetylcholine). There was significant impairment of this mechanism at 2 weeks, which was further impaired at 5 months. Values are mean plus or minus standard error of mean. ${ }^{*} p<0.05$ versus control values.

created a shunt of sufficient magnitude to be considered clinically significant.

Over the time course of this study, this shunt did not produce pulmonary hypertension. As shown in Table I, there was no difference in pulmonary arterial systolic, diastolic, or mean pressure at any of the points in data collection. Likewise, there were no changes in left atrial pressure. Thus the transpulmonary gradient did not change (Table I).

There was a progressive dysfunction of endothelium-dependent cGMP-mediated pulmonary vasorelaxation (response to acetylcholine). As shown in Fig. 3, acetylcholine $10^{-6} \mathrm{~mol} / \mathrm{L}$ produced $95 \% \pm$ $5 \%$ relaxation of pulmonary arterial rings in control specimens. This was not different at 3 days. However, at 2 weeks, acetylcholine $10^{-6} \mathrm{~mol} / \mathrm{L}$ produced only $84 \% \pm 5 \%$ relaxation $(p<0.05$ versus control value). At 5 months, this mechanism of pulmonary vasorelaxation was significantly impaired and acetylcholine $10^{-6} \mathrm{~mol} / \mathrm{L}$ produced only $36 \% \pm 6 \%$ relaxation ( $p<0.05$ versus control value).

Likewise, there was progressive dysfunction of endothelium-independent cGMP-mediated pulmonary vasorelaxation (response to sodium nitroprusside). As shown in Fig. 4, the vasorelaxing response to sodium nitroprusside $10^{-6} \mathrm{~mol} / \mathrm{L}$ was not different from control values at 3 days or at 2 weeks. However, by 5 months, there was significant impairment of this mechanism and sodium nitroprusside $10^{-6} \mathrm{~mol} / \mathrm{L}$ produced only $69 \% \pm 6 \%$ relaxation versus $100 \%$ relaxation in control specimens $(p<$ 0.05 versus control value).

The third mechanism of pulmonary vasodilation studied was $\beta$-adrenergic cAMP-mediated pulmonary vasorelaxation (response to isoproterenol). As shown in Fig. 5, there was no dysfunction of this mechanism at 3 days. However, at 2 weeks, this mechanism was significantly impaired and isoproterenol produced only $62 \% \pm 7 \%$ relaxation versus $95 \% \pm 6 \%$ relaxation in control specimens $(p<0.05$ versus control value). At 5 months, this mechanism was further impaired and isoproterenol produced only $55 \% \pm 5 \%$ relaxation $(p<0.05$ versus control value).

\section{Discussion}

Net pulmonary vascular tone results from the balance of the mechanisms of pulmonary vasorelaxation and vasoconstriction. In the normal lung, the low pulmonary vascular smooth muscle tone may at least in part be due to the basal endothelial release of the vasodilator nitric oxide. ${ }^{6}$ Endothelium-derived nitric oxide lowers pulmonary vascular tone by stimulating guanylate cyclase in subjacent vascular smooth muscle cells to generate cGMP, which produces pulmonary vascular smooth muscle relaxation. ${ }^{10}$ If the mechanisms of pulmonary vasorelaxation are impaired, the net pulmonary vascular tone may be tipped in favor of pulmonary vasoconstriction. In addition, impairment of the mechanisms of 


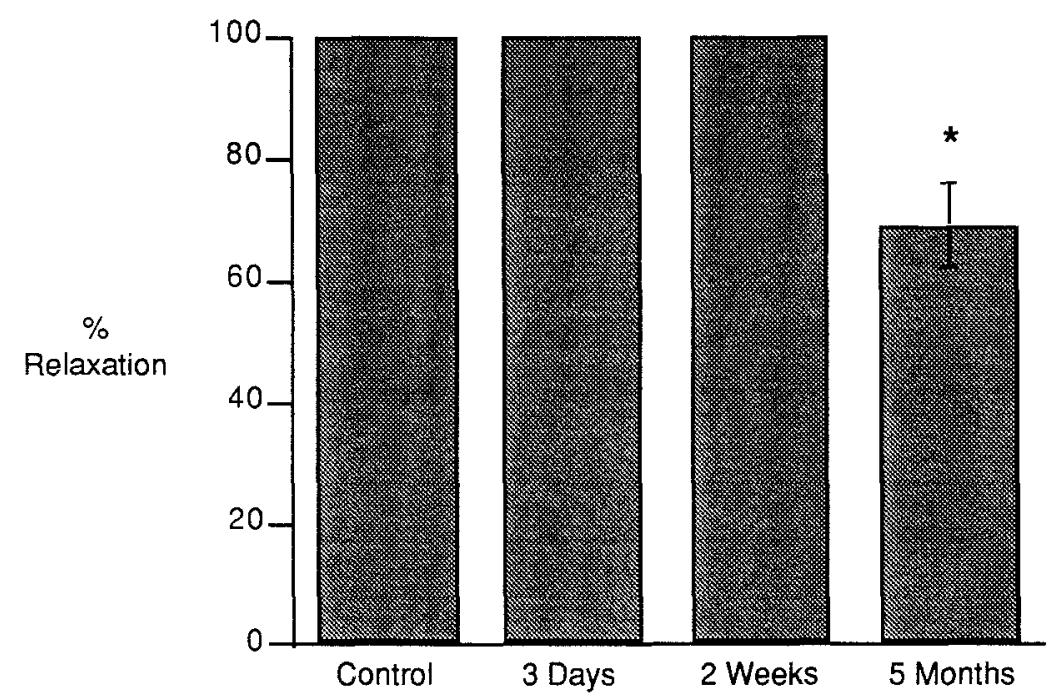

Fig. 4. Endothelium-independent cGMP-mediated pulmonary vasorelaxation (response to sodium nitroprusside). This mechanism of pulmonary vasorelaxation was significantly impaired at 5 months. Values are mean plus or minus standard error of mean. * $p<0.05$ versus control values.

pulmonary vasorelaxation may result in an exaggerated pulmonary vasoconstricting response to circulating or local vasoconstricting agonists. ${ }^{6}$ In addition to cGMP-mediated relaxation, the other principal intracellular mediator of pulmonary vasorelaxation is cAMP. ${ }^{7}$ The results of this study suggest that both cGMP- and cAMP-mediated mechanisms of pulmonary vasorelaxation become dysfunctional in the setting of a left-to-right shunt.

Other large animal models have been used to create structural changes in the pulmonary circulation as a result of a left-to-right shunt. However, the changes in pulmonary vasomotor control mechanisms caused by chronic high pulmonary blood flow have not previously been described. Creation of an aortopulmonary arterial anastomosis in pigs ${ }^{11,12}$ or $\operatorname{dog} s^{13,14}$ rapidly produces muscular changes in the pulmonary vasculature that resemble the changes found in human beings with left-to-right shunts. These large animal models increase both pulmonary arterial pressure and flow. By simultaneously changing both of these injurious stimuli, it is difficult to separate the effects of pressure from those of flow. The model used in the present study offered an advantage by creating high pulmonary flow without pulmonary hypertension. This permitted an examination of the influence of high pulmonary flow alone on pulmonary vasomotor control mechanisms.

However, certain limitations of this model must be acknowledged. First, this model was not an intracardiac shunt. It is possible that a model in which an intracardiac shunt was created might have yielded higher pulmonary arterial pressure or a different pattern of pulmonary vasomotor dysfunction. Second, the hemodynamic measurements were by necessity made with the animals under general anesthesia. It is therefore possible that a small increase in pulmonary arterial pressure was present in these animals but not measurable under general anesthesia. Third, the animals used in the present study were mature. In the clinical situation, the left-to-right shunt is present from birth. Fourth, generation of high pulmonary artery blood flow by creation of a left-to-right shunt unavoidably raises the $\mathrm{PO}_{2}$ of the pulmonary arterial blood; it is impossible to determine what influence, if any, the increased $\mathrm{PO}_{2}$ had in the production of pulmonary vasomotor dysfunction. Because of some of these limitations, it may not be possible to directly extrapolate the findings of the present study to human beings. Nonetheless, the findings of the present study do suggest that chronic high pulmonary flow produces dysfunction of the mechanisms of pulmonary vasorelaxation.

The structural changes produced in the pulmonary circulation as a result of chronic high pulmonary arterial flow have been well characterized. In 1958, Heath and Edwards ${ }^{4}$ described the progression of changes beginning with the reversible changes of intimal hyperplasia and medial hypertrophy and progressing to the irreversible changes of angiomatous malformation and fibrinoid necrosis. 


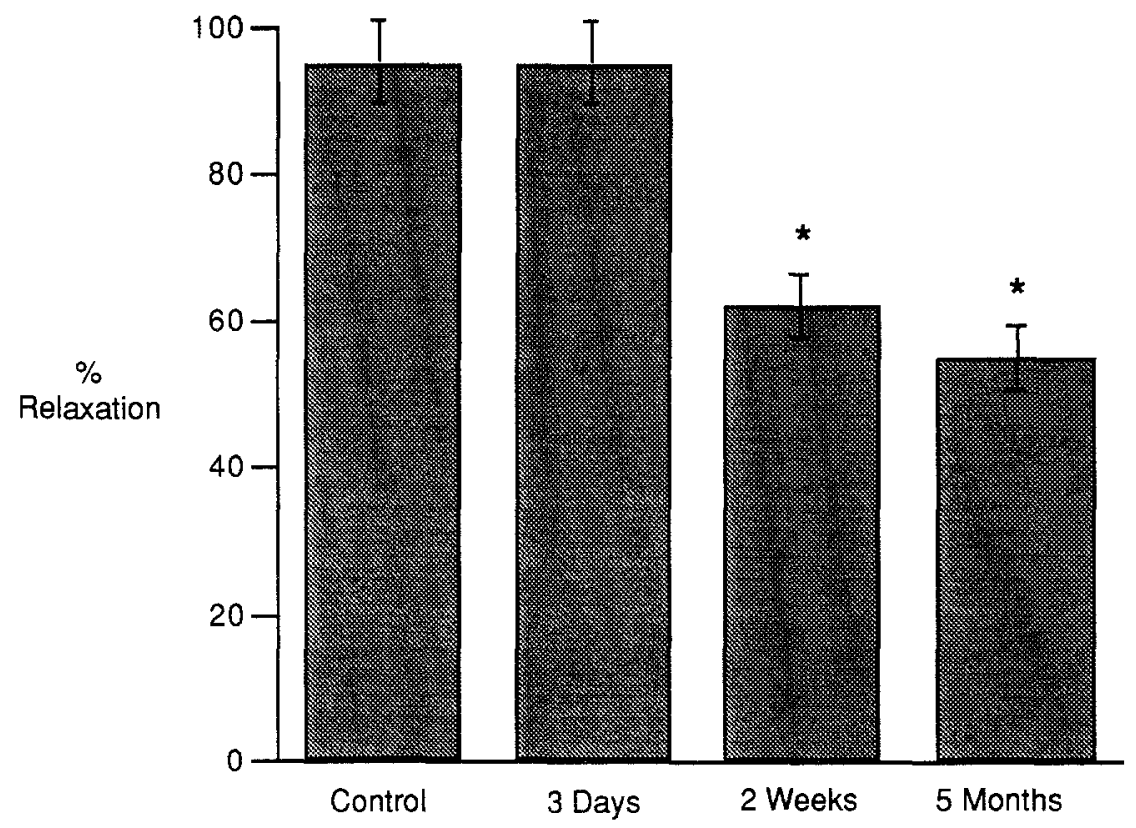

Fig. 5. $\beta$-Adrenergic cAMP-mediated pulmonary vasorelaxation (response to isoproterenol). This mechanism of vasorelaxation was significantly impaired by 2 weeks. Values are mean plus or minus standard error of mean. ${ }^{*} p<0.05$ versus control values.

The mechanisms by which these changes are produced remain unclear. Most current theories invoke endothelial cell injury by high pulmonary flow and pressure as an inciting event. Endothelial cell injury may result in release of proteases into the subendothelium, leading to destruction of the basement membrane and extracellular matrix proteins. This in turn may trigger both hypertrophy and hyperplasia of pulmonary vascular smooth muscle cells, leading to increased muscularization of small vessels. ${ }^{15,16}$ These structural changes have been clearly associated with progressively increasing pulmonary arterial pressure. ${ }^{17,18}$

Pulmonary hypertension as a result of an increased PVR may greatly complicate the perioperative treatment of patients undergoing correction of a left-to-right shunt. This pulmonary hypertension may be derived from the structural changes of the pulmonary circulation. However, in addition, the pulmonary circulation of these patients is characterized by a "reactive" or an exaggerated vasoconstrictive component of PVR. ${ }^{16}$ The mechanisms of this exaggerated pulmonary vasoconstriction are unclear, but circulating or local vasoconstricting agonists such as catecholamines, ${ }^{19}$ thromboxanes, ${ }^{20}$ leukotrienes, ${ }^{21}$ and other pulmonary vasoconstricting agonists $^{22}$ may all contribute. The most extreme example of this exaggerated pulmonary vasocon- striction is a "pulmonary hypertensive crisis," in which severe pulmonary vasospasm is refractory to vasodilator therapy and may be lethal.

Rather than examining the pulmonary vascular structural changes induced by high pulmonary blood flow, the present study focused instead on intrinsic mechanisms of pulmonary vasomotor control: cGMP-mediated and cAMP-mediated pulmonary vasorelaxation. The findings of the present study demonstrated progressive dysfunction of both endothelium-dependent and endothelium-independent cGMP-mediated pulmonary vasorelaxation and $\beta$-adrenergic cAMP-mediated pulmonary vasorelaxation in a canine model of a left-to-right shunt. Although these signal transduction pathways were shown to become dysfunctional, the present study does not elucidate exactly where in these pathways the impairment was produced. This pulmonary vasomotor dysfunction occurred before the development of pulmonary hypertension or an increase in transpulmonary gradient. The present study did not examine what structural changes, if any, were produced in the pulmonary vascular bed. However, because the animals in the present study did not have pulmonary hypertension, it is tempting to speculate that the impairment in pulmonary vasorelaxation preceded structural changes.

The current findings may offer some mechanistic 
insight into the development of pulmonary hypertension with chronic high pulmonary blood flow. The present study demonstrated significant progressive impairment of cGMP- and cAMP-mediated mechanisms of pulmonary vasorelaxation in the setting of a left-to-right shunt. Such dysfunction of vasorelaxation may help tip the net balance of pulmonary vasomotor tone toward vasoconstriction and contribute to exaggerated pulmonary vasoconstriction in response to local or circulating vasoconstricting agonists.

\section{REFERENCES}

1. Cartmill T, DuShane JW, McGoon DC, et al. Results of repair of ventricular septal defect. J THORAC CARDIOVASC SURG 1966;52:486-99.

2. Clarkson PM, Neutze JM, Wardill JC, et al. The pulmonary vascular bed in patients with complete transposition of the great arteries. Circulation 1976; 53:539-42.

3. Rabinovitch M. Problems of pulmonary hypertension in children with congenital cardiac defects. Chest 1988;93:S119-26.

4. Heath D, Edwards JE. The pathology of hypertensive pulmonary vascular disease. Circulation 1958;18:533-7.

5. Roberts JD, Lang P, Bigatello LM, et al. Inhaled nitric oxide in congenital heart disease. Circulation 1993;87:447-53.

6. McIntyre RC Jr, Harken AH, Fullerton DA. Mechanisms of pulmonary vasomotor function in normal and injured lung. Surgery 1994;115:273-5.

7. Fullerton DA, Hahn AR, Banerjee A, Harken AH. Pulmonary vascular smooth muscle relaxation by cGMP- versus cAMP-mediated mechanisms. J Surg Res 1994;57:259-63.

8. Fullerton DA, Mitchell MB, McIntyre RC Jr, et al. Cold ischemia and reperfusion each produce pulmonary vasomotor dysfunction in the transplanted lung. J Thorac Cardiovasc Surg 1993;106:1213-7.

9. Fullerton DA, Mitchell MB, McIntyre RC Jr, Campbell DN, Grover FL. Lung transplantation with cardiopulmonary bypass exaggerates pulmonary vasomotor dysfunction in the transplanted lung. J THORAC Cardiovasc Surg 1995;109:212-7.

10. Murad F. Cyclic guanosine monophosphate as a mediator of vasodilation. J Clin Invest 1986;78:1-5.

11. Rendas A, Lennox S, Reid L. Aorta-pulmonary shunts in growing pigs. J THORAC CARDIOVASC SuRG 1979;77:109-18.

12. Rendas A, Reid L. Pulmonary vasculature of piglets after correction of aorta-pulmonary shunts. J THORAC CARdiovasc Surg 1983;85:911-6.

13. Ferguson DJ, Vargo RL. The relation of blood pressure and flow to the development and regression of experimentally induced pulmonary arteriosclerosis. Circ Res 1955;3:152-8.

14. Blank RH, Muller LD, Damman JF. Experimental pulmonary hypertension. Am J Surg 1961;101:143-53.

15. Maindardi CL, Dixit SN, Kang AH. Degradation of type IV collagen by a proteinase isolated from human polymorphonuclear leukocyte granules. J Biol Chem 1980;255:5435-41.

16. Rabinovitch M. Mechanisms of pulmonary hypertension in chronic high flow states. In: Weir EK, Reeves JT, eds. Pulmonary vascular physiology and pathophysiology. New York: Marcel Dekker, 1989:469-511.

17. Rabinovitch M, Keane JF, Fellows KE, Castaneda AR, Reid L. Quantitative analysis of the pulmonary wedge angiogram in congenital heart defects: correlation with hemodynamic data and morphometric findings in lung biopsy tissue. Circulation 1981;63:15264.

18. Rabinovitch M, Keane JF, Norwood WI, Castaneda AR, Reid L. Vascular structure in lung biopsy correlated with pulmonary hemodynamic findings after repair of congenital heart defects. Circulation 1984; 69:655-67.

19. Fullerton DA, St. Cyr JA, Albert JD, Grover FL. Hemodynamic advantage of left atrial epinephrine administration following cardiac surgery. Ann Thorac Surg 1993;56:1263-6.

20. Addonizio VP Jr, Smith JB, Strauss JF III, Colman RW, Edmunds LH. Thromboxane synthesis and platelet secretion during cardiopulmonary bypass with bubble oxygenation. J ThORAC CARDIOvasc SURG 1980;79:91-6.

21. Yokochill K, Olley PM, Sideris E, Hamilton F, Hurttanen D, Coceani F. Leukotriene D4: a potent vasoconstrictor of the pulmonary and systemic circulations in the newborn lamb. In: Samuelsson B, ed. Leukotrienes and other lipoxygenase products. New York: Raven Press, 1982:214-21.

22. Downing SW, Edmunds LH. Release of vasoactive substances during cardiopulmonary bypass. Ann Thorac Surg 1992;54:1236-43. 